\title{
Análise dos Acordos Assinados pelo Brasil e pela Argentina na Área de Energia entre 1995 e 2010
}

\section{Analysis of the Energy Agreements Signed by Brazil and Argentina between 1995 and 2010}

\author{
Lucas Marques Feitosa \\ Universidade Federal da Paraíba (UFPB) \\ E-mail: lucaas.feitosa@hotmail.com
}

Resumo: Após os problemas energéticos enfrentados nas décadas de 70 e 80, as discussões sobre a segurança energética adentraram nas políticas dos países ao redor do mundo. Isso não foi diferente no Brasil, já que este era um país que era dependente do petróleo que vinha do exterior. Portanto, ao chegarem ao poder, tanto FHC quanto Lula desenvolveram políticas que permitissem o abastecimento dos recursos energéticos necessários pelo Brasil. Dentro desse quadro a Argentina aparece como o país que mais estabeleceu acordos na área de energia com o Brasil dentro da América do Sul. Contudo, ao longo do estudo, notou-se que houveram algumas alternâncias na forma como as políticas energéticas de cada período foram conduzidas. Pode-se apontar, por exemplo, que durante o governo FHC os combustíveis fósseis foram os recursos mais privilegiados, enquanto nos mandatos de Lula os biocombustíveis passam a receber uma maior atenção. Portanto, a partir dessas considerações, o presente trabalho busca realizar uma discussão de forma exploratória e descritiva sobre o atual debate sobre segurança energética, observar quais foram as continuidades e as descontinuidades da PEB de cada um desses ex-presidentes e promover uma análise sobre os acordos energéticos firmados com a Argentina nesse período.

Palavras-chave: Segurança Energética; Brasil; Argentina; Acordos Energéticos.

\begin{abstract}
Following the energy problems faced in the 1970s and 1980s, discussions on energy security have entered the policies of countries around the world. This wasn't different in Brazil, since this was a country that was dependent on oil coming from abroad. Therefore, when they came to power, both FHC and Lula developed policies that would allow them to supply the energy resources needed by Brazil. Within this framework Argentina appears as the country that most established agreements in the area of energy with Brazil within South America. However, throughout the study, it was noticed that there were some alternations in the way the energy policies of each period were conducted. It can be pointed out, for example, that during the FHC government, fossil fuels were the most privileged resources, while in Lula's mandates, biofuels received greater attention. Therefore, based on these considerations, the present paper seeks to conduct an exploratory and descriptive discussion about the current energy security
\end{abstract}


FEITOSA, Lucas Marques. Análise dos Acordos Assinados pelo Brasil e pela Argentina na Área de Energia entre 1995 e 2010.

debate, to observe the continuities and discontinuities of the PEB of each of these former presidents, and to promote an analysis of the agreements signed with Argentina.

Keywords: Energy Security; Brazil; Argentina; Energy Agreements.

\section{Introdução}

Ter a capacidade de fornecer energia de forma segura é algo que os países ao redor do mundo vêm se preocupando ao longo dos anos, já que o consumo de energia está intrinsicamente ligado ao desenvolvimento econômico dos Estados (Medeiros, 2009). Essa preocupação que os países possuem acaba entrando na discussão sobre segurança energética, que segundo Barton et al é "uma condição na qual uma nação e todos, ou a maioria, dos seus cidadãos e suas empresas tem acesso a recursos energéticos suficientes a preços razoáveis por um futuro previsível, livre de riscos de uma grande interrupção do serviço." (Barton et al, 2004, p. 5). Portanto, para que esses requisitos sejam alcançados eles precisam desenvolver parcerias com outros países, já que alcançar a segurança energética não é algo que eles conseguem fazer sozinhos. Existem diversos fatores externos que podem afetar a segurança energética de um país, como por exemplo a volatilidade dos preços no mercado internacional, panes em sistemas elétricos e catástrofes naturais. Dessa forma, é sempre importante ter parceiros que permitam uma maior garantia no abastecimento energético interno.

Ao tratar sobre parceiros internacionais, a Argentina é historicamente um importante ator nas relações internacionais do Brasil. Farias (2011) aponta, por exemplo, que desde a proclamação da república as relações entre esses dois países são marcadas pela disputa pela hegemonia da América do Sul. Em meio a rivalidades e parcerias, a diplomacia brasileira se alternou ao longo dos anos em relação ao papel que o vizinho platino desempenharia na formulação das políticas externas brasileira, podendo ser considerado tanto um rival em meio aos objetivos brasileiros de conseguir um assento permanente no Conselho de Segurança das Nações Unidas, como também o principal parceiro do Brasil para a consolidação da integração regional na América do Sul (Farias, 2011).

Revista Brasileira de Políticas Públicas e Internacionais, v.4, n.1, julho/2019, pp. 82-104. 
FEITOSA, Lucas Marques. Análise dos Acordos Assinados pelo Brasil e pela Argentina na Área de Energia entre 1995 e 2010.

Portanto, tendo isso em mente, a pergunta central desse trabalho é saber quais foram as características principais da cooperação energética entre Brasil e Argentina entre 1995 e 2010. O objetivo desse artigo é observar a cooperação energética entre o Brasil e a Argentina a partir da análise dos acordos assinados entre esses dois países dentro do período que está sendo analisado. Além disso, também busca-se de forma específica adentrar no debate atual sobre segurança e complementaridade energética, discutir as continuidades e descontinuidades da Política Externa Brasileira dos governos dos dois presidentes tratados aqui e apontar os principais resultados encontrados na pesquisa, como por exemplo os principais recursos energéticos contemplados nos acordos, a cronologia dos atos e os tipos de $\operatorname{atos}^{1}$ assinados. A análise foi feita de forma descritiva e exploratória a partir do recolhimento dos atos assinados durante esse período entre esses dois países por meio da plataforma Concórdia pertencente ao Departamento de Atos Internacionais do Ministério das Relações Exteriores e também por meio de uma revisão bibliográfica sobre o assunto.

$\mathrm{O}$ artigo foi dividido em três seções, na qual a primeira apresenta as principais definições de segurança energética, e como ela se relaciona com o conceito de complementaridade energética. Pode-se dizer de forma inicial que esse é um conceito vago e com diversas definições, muitas vezes considerado até um termo guarda-chuva por abarcar diferentes temáticas (Ciuta, 2010). Na segunda parte identifica-se de forma geral as políticas externas dos governos FHC e Lula em relação à Argentina. Observa-se nessa parte tanto as continuidades quanto as descontinuidades, como por exemplo a busca por uma política de liderança realizada de forma natural no governo FHC para não gerar atritos com seu vizinho, enquanto no governo Lula isso se deu de forma mais proativa. Já na última seção é apresentado o resultado da análise dos atos assinados entre os dois países, mostrando os principais recursos energéticos identificados, os tipos de documentos realizados e os objetivos que foram firmados ao realizar as negociações.

\footnotetext{
${ }^{1}$ Um ato internacional "é um acordo firmado entre países, regido pelo direito internacional. São como "contratos" firmados entre pessoas jurídicas de direito internacional (Estados, organismos internacionais, etc.) com a finalidade de regulamentar determinadas situações e convergir interesses comuns ou antagônicos.” (Brasil, 2017).
}

Revista Brasileira de Políticas Públicas e Internacionais, v.4, n.1, julho/2019, pp. 82-104. 
FEITOSA, Lucas Marques. Análise dos Acordos Assinados pelo Brasil e pela Argentina na Área de Energia entre 1995 e 2010.

\section{Segurança e complementaridade energética: definições e suas importâncias}

A discussão a respeito do termo segurança energética é um fenômeno que advém desde o início do século XX, quando a esquadra britânica, na primeira guerra mundial, resolveu alterar o combustível dos seus navios, passando do carvão para óleo diesel, permitindo que as suas embarcações se movessem em uma maior velocidade em relação aos barcos germânicos (Simões, 2007, p.12). Essa decisão fez com que a Grã-Bretanha parasse de depender do carvão vindo do País de Gales e ficasse sujeita ao fornecimento inseguro do petróleo vindo da antiga Pérsia. (Yergin, 2006, p. 69). Foi na decorrência dessa decisão que Santos et al (2013) afirma que a energia passou a ser atrelada tanto às decisões políticas quanto às decisões estratégicas.

Além disso, segundo Scheibe (2008), a crise do abastecimento energético causada pelos embargos ao petróleo em 1973 fez com que a energia se tornasse um tema discutido tanto na área de segurança, como na área de política internacional. Como boa parte dos países desenvolvidos dependem do petróleo e do gás natural derivados de zonas como a Rússia e o Oriente Médio, a segurança energética passou a ser um dos temas que mais preocupam as agendas dos governos, das organizações internacionais e das ONGs ao redor do mundo (Barufi, 2006; Ciuta, 2010), tendo em vista que a questão energética, de acordo com Ribeiro (2015), tornou-se um vetor de poder, influenciando tanto os interesses, como as políticas desenvolvidas pelos países. Ela afirma que isso fica evidente ao observar que são esses países mais poderosos e desenvolvidos que são aqueles que mais consomem energia.

O consumo de energia é tão importante para esses países porque, segundo Johansson (2013), a energia é um produto essencial para o bom funcionamento de uma sociedade, já que os recursos energéticos estão intrinsicamente ligados aos setores de produção e de consumo dos Estados a nível local, regional e global. Além disso, a energia também se mostra importante porque ela pode ser entendida pelos países tanto como uma fonte de poder, como também como uma ferramenta sociopolítica (Angulo, 2011). Além disso, Johansson (2013) afirma que "a disponibilidade de energia a baixo custo tem sido historicamente um dos principais fatores que contribuem para o desenvolvimento econômico e para um padrão de vida elevado." (Johansson, 2013, p. 199). Outro ponto importante que também vem levantando debates a respeito do consumo de energia é em relação aos efeitos que esse consumo pode causar ao meio ambiente.

Revista Brasileira de Políticas Públicas e Internacionais, v.4, n.1, julho/2019, pp. 82-104. 
FEITOSA, Lucas Marques. Análise dos Acordos Assinados pelo Brasil e pela Argentina na Área de Energia entre 1995 e 2010.

Paiva (2010) aponta que governos do mundo inteiro tem buscado superar o desafio que é suprir as necessidades da sociedade por energia de maneira sustentável ${ }^{2}$, influenciando diversos estudos relacionados a temática da segurança energética.

Portanto, sabendo da importância que a energia tem para as sociedades, é necessário entender quais são as principais conceitualizações de segurança energética. Inicialmente podese dizer que o termo segurança energética tem diversas definições que vão variar tanto de acordo com o contexto em que está sendo utilizado, como também pelo profissional ou o Estado que está utilizando o conceito. Chester (2009), por exemplo, afirma que o conceito de segurança energética é considerado abstrato ou até vago, e as suas definições podem se alternar tanto pela perspectiva de que é necessário ter acesso ininterrupto aos recursos energéticos, como pela noção de que um Estado não deve se tornar dependente da importação dos recursos de uma região específica, ou de que é necessário possuir uma variedade de recursos que permitam um fornecimento energético livre de choques externos e que garantam a autossuficiência energética. Por outro lado, Johansson (2013) afirma que frequentemente utiliza-se o conceito de segurança energética como sinônimo de "segurança de fornecimento", que neste caso seria definida como um "fornecimento de energia adequado, acessível e confiável." (Johansson, 2013, p. 199).

Chaudry et al (2011), vão afirmar que segurança energética, sob a perspectiva do governo britânico, pode ser dividida em três elementos, que seriam: segurança física (evitar interrupções físicas do consumo de energia); segurança do preço (evitar picos de preços desnecessários devido a desequilíbrios na oferta e na demanda e a operações de mercado ruins); e segurança geopolítica (evitar confiança indevida em nações específicas para manter graus máximos de liberdade na política externa) (Chaudry et al, 2011, p. 4). Yergin (2006), por sua vez, salienta que enquanto para alguns países desenvolvido a segurança energética se resume a disponibilidade suficiente de oferta a preços acessíveis, para outros países em desenvolvimento a preocupação vai ser com a forma que a variação dos preços dos recursos energéticos vai afetar as suas balanças de pagamento. Essas definições dadas por Chaudry et al (2011) e Yergin

\footnotetext{
2 A partir da definição de Angulo (2011), sustentabilidade seria a realização de "medidas que são buscadas para promover o uso racional de energia ao mesmo tempo que aumenta a sua produtividade, reduzindo os custos associados com a produção energética, como a poluição do meio ambiente" (Angulo, 2011, p. 8).
}

Revista Brasileira de Políticas Públicas e Internacionais, v.4, n.1, julho/2019, pp. 82-104. 
FEITOSA, Lucas Marques. Análise dos Acordos Assinados pelo Brasil e pela Argentina na Área de Energia entre 1995 e 2010.

(2006) exemplificam bem a ideia de que um Estado pode ter uma visão específica e diferente de outros do que é segurança energética.

É importante salientar também que segurança energética não é algo que os países conseguem alcançar sozinhos. Pergher (2016) afirma, por exemplo, que "a administração conjunta dos recursos energéticos, há muito tempo, é temática central de grande número de processos integracionistas em várias regiões do globo" (Pergher, 2016, p. 59). Entretanto, Castro et al (2014) aponta que esse é um processo complexo, necessitando de estratégias que permitam que as barreiras políticas, econômicas, culturais e técnicas sejam superadas. Uma das estratégias que podem ser utilizadas para solucionar essas questões é a criação de normas e regras que permitam uma maior estabilidade na relação entre os países no momento de solução de controvérsias.

Dentro desse contexto, surge também a discussão sobre complementaridade energética. Complementaridade energética é um conceito basilar na discussão desse trabalho e, segundo Angulo (2011), ela caracteriza uma situação onde existem países em uma determinada localidade que detém uma grande produção e pouco consumo, e países que tem um alto consumo, mas pouca produção. Rodrigues (2012) afirma que por meio da complementaridade é possível utilizar os recursos energéticos de uma região de forma mais racional. Além disso, a complementaridade energética é importante porque ela permite diminuir os custos para atender a demanda energética por meio da energia que não é utilizada em países vizinhos, assim como também é possível aumentar a geração de energia e consequentemente aumentar também a oferta com preços mais competitivos no mercado. Outro ponto importante a respeito da integração por meio da complementaridade energética é que ela pode permitir que os países alcancem um desenvolvimento mútuo de longo prazo, superando certas adversidades que gerariam insegurança. Rodrigues (2012) destaca inclusive que o Brasil e a Argentina, que são objetos de análise deste trabalho, ao se integrarem energeticamente reduzem os custos das operações energéticas em 5\%, gerando maiores ganhos econômicos para ambos os países, além de terem maior confiabilidade que terão acesso à energia de forma segura.

Revista Brasileira de Políticas Públicas e Internacionais, v.4, n.1, julho/2019, pp. 82-104. 
FEITOSA, Lucas Marques. Análise dos Acordos Assinados pelo Brasil e pela Argentina na Área de Energia entre 1995 e 2010.

\section{Políticas externas de FHC e Lula: continuidades e descontinuidades}

Para analisar como ocorreu a cooperação no setor de energia entre o Brasil e a Argentina durante os governos de Fernando Henrique Cardos e de Lula da Silva é necessário de antemão entender de forma simplificada como era orientada a política externa brasileira durante esses dois períodos e como a Argentina se encaixa dentro da diplomacia brasileira.

Em primeiro lugar, para destacar a importância da Argentina no arcabouço da diplomacia brasileira, é possível afirmar, de acordo com Granato (2012), que:

Desde o final do século XIX, as relações bilaterais argentino-brasileiras evoluíram de uma fase inicial de rivalidade para uma cooperação baseada no entendimento de que uma aliança estratégica, entre ambos os países, constituiria o "motor" da integração regional na América do Sul. Nesse sentido, o compromisso argentino-brasileiro, que une os dos maiores Estados da região, é essencial para a condução e o fortalecimento do processo de união sul-americana em curto, médio e longo prazo. (Granato, 2012, p. 71).

Portanto, sabendo que a cooperação entre o Brasil e a Argentina é de extrema importância para o desenvolvimento tanto dos próprios países, como para a América do Sul, o que se pode dizer inicialmente sobre a política externa do governo FHC é que ela se iniciou com a busca de alterar o paradigma da autonomia pela distância, que foi presente durante o período anterior, pela autonomia da integração ${ }^{3}$. Vigevani e Oliveira (2003) vão dizer que essa era uma agenda mais proativa por parte do Brasil, que determinava que "o país deve ampliar o poder de controle sobre o seu destino, e a resolução de seus problemas internos é melhor viabilizada pela participação ativa na elaboração das normas e das pautas de conduta da ordem mundial." (Vigevani \& Oliveira, 2003, p. 2).

Os tomadores de decisões brasileiros acreditavam que por meio dessa atuação internacional, que envolvia o ajuste dos interesses brasileiros às tendências modernas e liberais, a política externa brasileira contribuiria para que o país alcançasse o seu principal objetivo: o desenvolvimento econômico. Vigevani e Oliveira (2003) apontam inclusive que a efetivação

\footnotetext{
${ }^{3}$ Vigevani e Cepaluni (2007) definem autonomia pela integração como "a adesão aos regimes internacionais, inclusive os de cunho liberal, sem a perda da capacidade de gestão da política externa; nesse caso, o objetivo seria influenciar a própria formulação dos princípios e das regras que regem o sistema internacional" (Vigevani \& Cepaluni, 2007, p. 283).
}

Revista Brasileira de Políticas Públicas e Internacionais, v.4, n.1, julho/2019, pp. 82-104. 
FEITOSA, Lucas Marques. Análise dos Acordos Assinados pelo Brasil e pela Argentina na Área de Energia entre 1995 e 2010.

dessa inserção internacional brasileira ocorreu "através de uma participação que o governo definia como construtiva e propositiva no que tange aos assuntos da nova agenda internacional: meio ambiente, direitos humanos, não proliferação nuclear, integração regional na América do Sul, respeito à democracia." (Vigevani \& Oliveira, 2003, p. 3).

No que tange a participação da Argentina na política externa durante o governo FHC "mesmo no momento onde as divergências ganharam maior intensidade, em janeiro de 1999, com a desvalorização do real, a política do governo FHC foi a de tentar formas de entendimento" (Vigevani \& Oliveira, 2003, p. 17). Ou seja, buscando deixar uma boa imagem do Brasil, a política externa do governo Cardoso buscava uma melhoria nas relações entre os dois países, inclusive no que diz respeito a uma liderança no entorno regional. A ideia era que essa liderança ocorresse de forma natural sem provocar desentendimentos com a Argentina. Essa afirmação pode ser evidenciada, por exemplo, por um discurso realizado pelo próprio Cardoso no qual ele afirma que:

Entre uma cadeira no Conselho e a amizade com a Argentina e com nossos vizinhos, ficaríamos com a segunda. Eu via como melhor caminho para nosso país ingressarmos no clube dos desenvolvidos, na época o G-7, graças ao nosso trabalho e à integração com nossos vizinhos, em vez de lutarmos por uma posição política, desprestígio, para a qual talvez não tivéssemos o apoio deles, tão importante para o crescimento e para a consolidação de nossa experiência integradora. (Cardoso apud Vigevani \& Cepaluni, 2007, p. 305).

Já na área de energia, durante os dois governos de Fernando Henrique Cardoso houve um redirecionamento na política energética do Brasil, que passou a descobrir novos parceiros de cooperação energética na região, superando parceiros antigos como Iraque e Arábia Saudita. A questão nuclear passou a receber maior atenção, como é destacado por Vigevani e Oliveira (2003), ao demonstrarem que certas medidas foram tomadas entre esses dois países, como por exemplo a assinatura do acordo de criação da Agência Brasileiro-Argentina de Contabilidade e Controle de Materiais Nucleares (ABACC) e a assinatura do Acordo Quadripartite de Salvaguardas Nucleares entre o Brasil, a Argentina, a ABACC e a Agência Internacional de Energia Atômica.

Revista Brasileira de Políticas Públicas e Internacionais, v.4, n.1, julho/2019, pp. 82-104. 
FEITOSA, Lucas Marques. Análise dos Acordos Assinados pelo Brasil e pela Argentina na Área de Energia entre 1995 e 2010.

Em relação à política externa do governo Lula, o que se pode afirmar em primeiro lugar é que ela se diferenciava do seu antecessor devido a centralidade dessa política na atuação ativa do próprio presidente. Segundo Soares e Estensoro (2014), ao assumir a presidência em 2003, Lula definiu que a política externa do Brasil deveria ter como prioridade a integração da América do Sul. Eles afirmam que durante esse período foi dada uma maior atenção ao Mercosul, como também houve a realização de esforços para a efetivação da Unasul em 2008. Eles elucidam inclusive que "Neste exercício de integração, foram contempladas diversas atividades de cooperação regional que buscavam a superação conjunta dos desafios do desenvolvimento no continente." (Soares e Estensoro, 2014, p. 7).

Segundo Ribeiro (2015), durante os governos de Lula da Silva a busca pelo desenvolvimento e pela autonomia foram peça central da política externa brasileira, na qual o governo buscou diversificar seus parceiros internacionais, fazendo com que essa diplomacia ficasse conhecida como autonomia pela diversificação ${ }^{4}$. Como ocorreu durante o governo FHC, houve novamente uma mudança de paradigma na política externa brasileira, na qual nesse momento o Brasil buscaria diversificar suas parcerias, dando maior atenção a países em desenvolvimento e países do sul global, características das relações sul-sul.

Como houve uma mudança de paradigma na agenda diplomática brasileira, isso se refletiu na participação da Argentina na formulação dessa agenda nesse período. Segundo Almeida (2004), o vizinho platino obteve uma mudança na perspectiva em que o Brasil o enxergava. De acordo com esse autor, enquanto no governo FHC a Argentina era um parceiro estratégico em meio a outros, no governo Lula a Argentina era o principal parceiro estratégico. No entanto, como o Brasil modificou a sua estratégia na busca pela liderança regional em relação ao governo anterior, acreditando que era necessário uma atuação mais ativa para alcançar esse objetivo, “o governo de Néstor Kirchner (2003-2007) procurou dar resposta ao poderio "sul-americano" do Brasil, para isso adotou estratégias que pudessem contrabalançar o

\footnotetext{
${ }^{4}$ De acordo com Vigevani e Cepaluni (2007), a autonomia pela diversificação pode ser entendida "como a adesão do país aos princípios e às normas internacionais por meio de alianças Sul-Sul, inclusive regionais, e de acordos com parceiros não tradicionais (China, Ásia-Pacífico, África, Europa Oriental, Oriente Médio etc.), pois acreditase que eles reduzem as assimetrias nas relações externas com países mais poderosos e aumentam a capacidade negociadora nacional" (Vigevani \& Cepaluni, 2007, p. 283).
}

Revista Brasileira de Políticas Públicas e Internacionais, v.4, n.1, julho/2019, pp. 82-104. 
FEITOSA, Lucas Marques. Análise dos Acordos Assinados pelo Brasil e pela Argentina na Área de Energia entre 1995 e 2010.

peso político econômico do seu vizinho.” (Braga, 2017, p. 7). Portanto, essas relações entre Brasil e Argentina passam a ser mais enfatizadas não só de forma bilateral, mas também em meio às organizações regionais.

No que diz respeito à política de energia do ex-presidente Lula, Simões (2007) destaca que os biocombustíveis tiveram grande importância tanto para o desenvolvimento das políticas de energia, como também para a agenda da política externa desse governo, em especial o etanol. Durante o governo de Lula os biocombustíveis deixaram de ser uma commoditie voltado simplesmente para consumo interno e para exportação, e passou ser prioridade na diplomacia brasileira aparecendo como uma forma de obter retorno político e econômico pelo governo brasileiro em relação aos demais países. Medeiros (2009) exemplifica essa afirmação ao demonstrar que durante o segundo mandato de Lula o Brasil priorizou o etanol em meio ao mercado internacional, com o intuito de obter mais destaque em meio aos países emergentes, e consolidar a posição do Brasil como um global player.

Beltrame (2008) relata que em seus encontros com líderes de outros países durante suas viagens ao exterior a temática dos biocombustíveis era tão importante nos diálogos realizados, que o presidente Lula se transformou no "garoto propaganda do etanol" (Beltrame, 2008, p. 5). Segundo Hage (2011), ao encontrar-se com líderes como George W. Bush e ao participar da abertura da Assembleia Geral da ONU em 2007, Lula buscava apresentar o Brasil como um país altamente capaz de produzir álcool combustível. O próprio ex-diretor do Departamento de Energia do Ministério das Relações Exteriores elucida inclusive que:

A determinação do Presidente em difundir o emprego de biocombustíveis no mundo é, sem dúvida, uma das marcas de sua administração. A energia é elemento fundamental para o crescimento e o desenvolvimento das sociedades modernas. A vantagem comparativa do Brasil em relação aos biocombustíveis pode ser fundamental para a consolidação do desenvolvimento do País e do seu novo papel no mundo. (Simões, 2007, p. 11).

Portanto, para concluir essa seção da discussão e facilitar a observação da discussão é possível ver de forma resumida no Quadro 1 quais foram as principais políticas desenvolvidas nos dois governos, apresentando as semelhanças, diferenças, continuidades e descontinuidades.

Revista Brasileira de Políticas Públicas e Internacionais, v.4, n.1, julho/2019, pp. 82-104. 
FEITOSA, Lucas Marques. Análise dos Acordos Assinados pelo Brasil e pela Argentina na Área de Energia entre 1995 e 2010.

Quadro 1: Política Externa de FHC e Lula: Continuidades e Descontinuidades

\begin{tabular}{|l|l|}
\hline FHC & LULA \\
\hline Autonomia pela integração & Autonomia pela diversificação \\
\hline Agenda diplomática proativa & Agenda diplomática proativa \\
\hline $\begin{array}{l}\text { Principal objetivo: desenvolvimento } \\
\text { econômico }\end{array}$ & $\begin{array}{l}\text { Principal objetivo: integração da América do } \\
\text { Sul }\end{array}$ \\
\hline Política realizada por diplomatas de carreira & $\begin{array}{l}\text { Política realizada de forma proativa pelo } \\
\text { próprio Presidente. }\end{array}$ \\
\hline $\begin{array}{l}\text { Política desenvolvida com a Argentina de } \\
\text { forma harmoniosa, considerando-a um } \\
\text { parceiro estratégico }\end{array}$ & $\begin{array}{l}\text { Política desenvolvida em que a Argentina era } \\
\text { considerada o principal parceiro brasileiro }\end{array}$ \\
\hline $\begin{array}{l}\text { Ajuste da diplomacia a tendências liberais e } \\
\text { modernas }\end{array}$ & $\begin{array}{l}\text { Busca por parceiros em desenvolvimento e } \\
\text { pertencentes ao sul global }\end{array}$ \\
\hline $\begin{array}{l}\text { Busca pela liderança regional de forma } \\
\text { natural }\end{array}$ & Busca pela liderança regional de forma ativa \\
\hline
\end{tabular}

Fonte: Elaborado pelo autor.

\section{Análise dos acordos com a Argentina na área de energia}

Sabendo então sobre o papel recebido pela Argentina durante os dois governos analisados e qual a orientação da política energética de cada um, agora será feita uma análise sobre os números gerais e o conteúdo dos atos internacionais realizados com esse país na área de energia. Busca-se observar as semelhanças e diferenças entre o governo FHC e Lula a partir da observação do número de atos realizados, os recursos energéticos contemplados nos atos, que tipo de documento estava sendo assinado, entre outras informações. Esses atos foram divididos de acordo com a importância que a temática energética recebe em cada um deles. Os atos que falam exclusivamente sobre energia foram classificados como atos de temática única. Já os atos que falam sobre mais de uma temática, mas que dão destaque aos assuntos energéticos foram denominados como atos de temática relevante. Já os atos que a energia recebe uma menção sem destaque foram chamados de atos de temática acessória.

Em primeiro lugar, para demonstrar um dos motivos pelos quais a Argentina foi escolhida para a presente análise, e porque ela é considerada nesse trabalho o principal parceiro

Revista Brasileira de Políticas Públicas e Internacionais, v.4, n.1, julho/2019, pp. 82-104. 
FEITOSA, Lucas Marques. Análise dos Acordos Assinados pelo Brasil e pela Argentina na Área de Energia entre 1995 e 2010.

energético do Brasil, é preciso salientar que ela é o país da América do Sul que mais estabeleceu acordos energéticos com o Brasil tanto no governo FHC quanto no governo Lula. Como é possível ver nos gráficos 1 e 2, a Argentina no governo FHC realizou 10 atos com o Brasil, enquanto no governo Lula esse número subiu para 15.

Gráfico 1: Número de Atos realizados por país no governo FHC

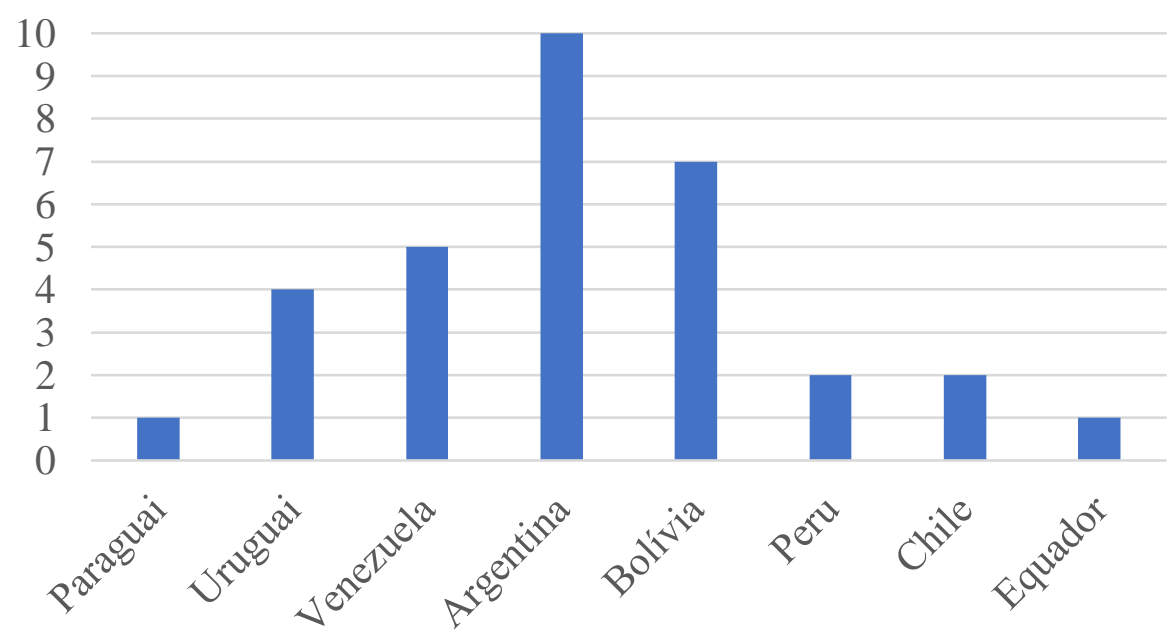

Fonte: Elaborado pelo autor.

Gráfico 2: Número de Atos realizados por país no governo Lula

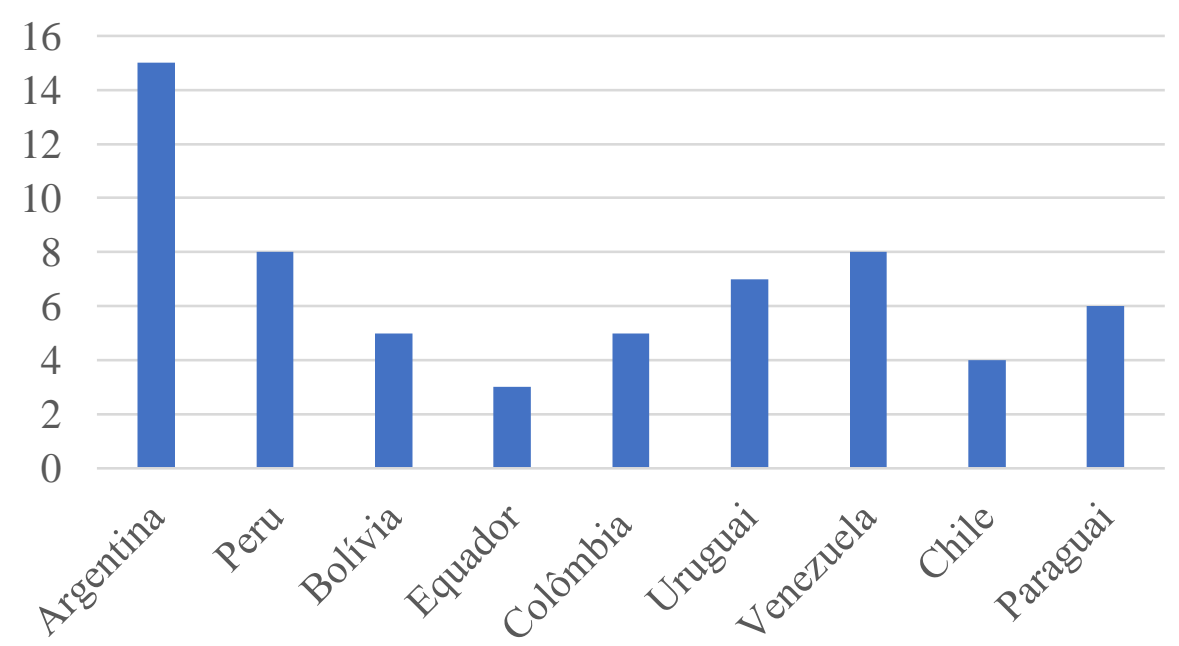

Fonte: Elaborado pelo autor.

Revista Brasileira de Políticas Públicas e Internacionais, v.4, n.1, julho/2019, pp. 82-104. 
FEITOSA, Lucas Marques. Análise dos Acordos Assinados pelo Brasil e pela Argentina na Área de Energia entre 1995 e 2010.

Em relação à temática dos atos, o governo FHC apresenta cinco atos de temática única, representando $50 \%$ do total, quatro de temática relevante e um de temática acessória. Já no governo Lula foram oito atos de temática única, representando mais da metade dos atos realizados, sete de temática relevante e nenhum de temática acessória. Esses números podem sugerir que quando a energia era discutida entre o Brasil e a Argentina tanto no governo FHC, quanto no governo Lula, ela representava um assunto importante que necessitava prioridade ao discuti-la. As tabelas 1 e 2 apontam os números encontrados em cada um dos dois governos.

Tabela 1: Número de Atos por Temática no Governo FHC

\begin{tabular}{l|l|l|l}
\hline Temática & Temática Única & Temática Relevante & Temática Acessória \\
\hline $\begin{array}{l}\text { Quantidade } \\
\text { Porcentagem }\end{array}$ & 5 & 4 & 1 \\
\hline
\end{tabular}

Fonte: Resultados da pesquisa.

Tabela 2: Número de Atos por Temática no Governo Lula

\begin{tabular}{l|l|l|l}
\hline Temática & Temática Única & Temática Relevante & Temática Acessória \\
\hline Quantidade & 8 & 7 & 0 \\
Porcentagem & $53,3 \%$ & $46,6 \%$ & $0 \%$ \\
\hline
\end{tabular}

Fonte: Resultados da pesquisa.

Portanto, a partir dessa informação da quantidade de atos realizados em cada governo, é preciso verificar quantos atos foram realizados por ano. No governo FHC, por exemplo, observou-se que nos anos de 1995, 1998, 1999 e 2000 não foi realizado nenhum ato assinado com a Argentina na temática energética, ou seja, somente em quatro dos oito anos que esteve no poder Cardoso assinou acordos com a Argentina. $\mathrm{O}$ ano de maior destaque foi o ano de 1997, com 5 atos realizados, seguidos por uma bruta queda nos anos subsequentes, voltando a realizar acordos com o seu vizinho somente no ano de 2001. Já nos mandatos de Lula da Silva verifica-se que somente no ano de 2004 não foi assinado nenhum tipo de documento com a Argentina. O ano de 2005 foi o ano em que se realizou um maior número de esforços

Revista Brasileira de Políticas Públicas e Internacionais, v.4, n.1, julho/2019, pp. 82-104. 
FEITOSA, Lucas Marques. Análise dos Acordos Assinados pelo Brasil e pela Argentina na Área de Energia entre 1995 e 2010.

cooperativos, sendo realizados 5 atos, sofrendo uma queda nos números ano seguinte, mas voltando a subir em 2008.

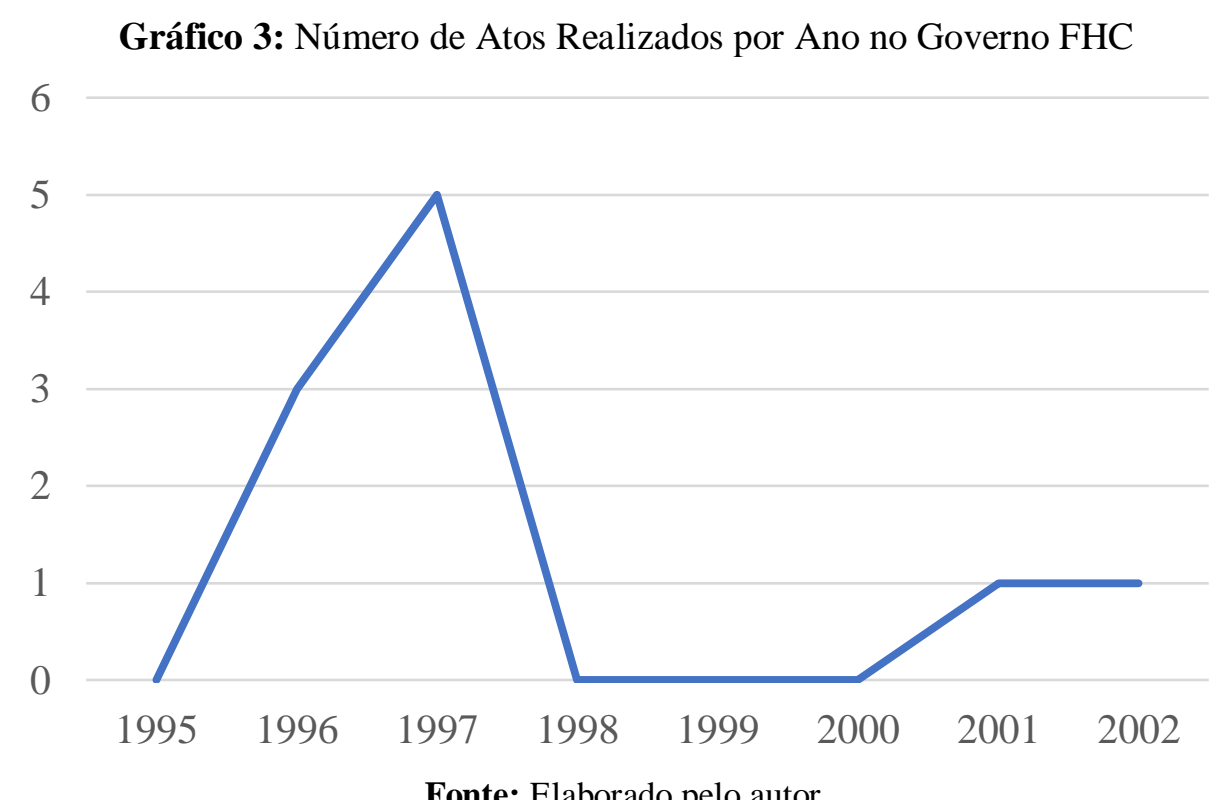

Fonte: Elaborado pelo autor.

Gráfico 4: Número de Atos Realizados por Ano no Governo Lula

6

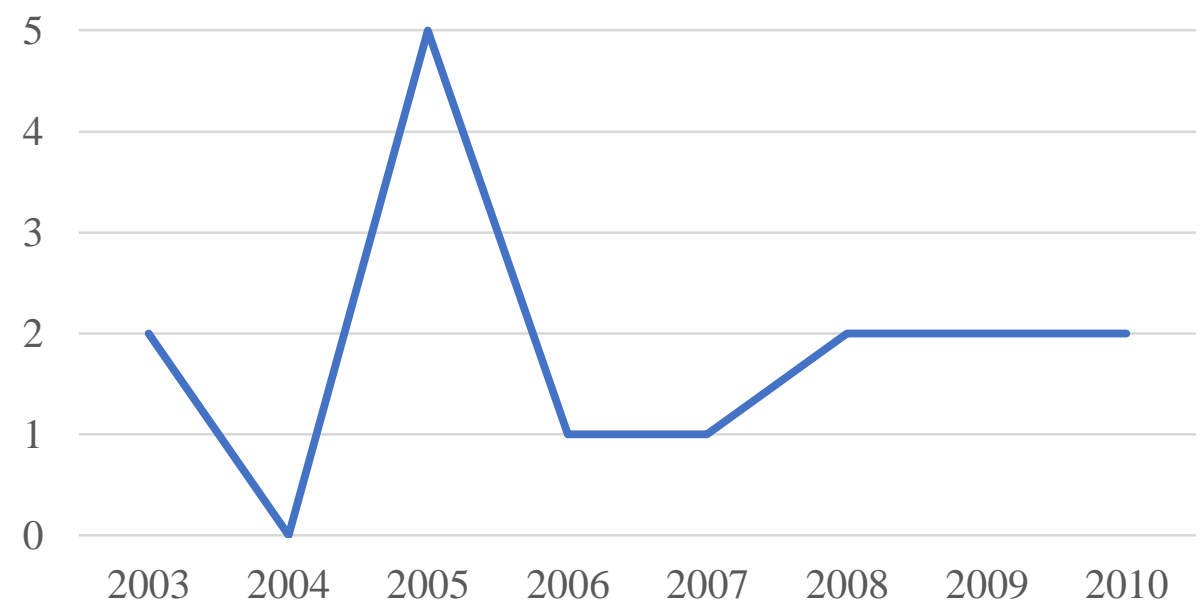

Fonte: Elaborado pelo autor.

Outra informação importante a respeito dos atos realizados é sobre os recursos energéticos que estiveram presentes nas discussões. No governo FHC o destaque principal vai Revista Brasileira de Políticas Públicas e Internacionais, v.4, n.1, julho/2019, pp. 82-104. 
FEITOSA, Lucas Marques. Análise dos Acordos Assinados pelo Brasil e pela Argentina na Área de Energia entre 1995 e 2010.

para o gás natural, sendo o recurso que mais apareceu nos acordos, sendo mencionado em seis deles. O termo energia elétrica também foi bastante pertinente nas discussões, aparecendo cinco vezes, sendo seguido pela energia nuclear e pela hidrelétrica, aparecendo quatro vezes cada. A energia elétrica é um destaque nas negociações entre esses dois países porque a proximidade existente entre ambos permite que seja possível realizar uma integração dos sistemas elétricos dos dois países, que foi objetivo da assinatura de alguns acordos entre os dois países.

Sobre o governo Lula, há a aparição de novos termos utilizados nas negociações, como por exemplo a energia eólica, a energia solar e os biocombustíveis, que foi o carro chefe da política energética em que esteve no governo. No entanto, em relação à Argentina, quem obteve maior destaque entre 2003 e 2010 foi a energia nuclear, aparecendo em doze atos. Ao somar os biocombustíveis, o etanol e o biodiesel, esse tipo de fonte energética aparece sete vezes, sendo seguidos pela energia elétrica, mencionada em seis acordos. Há de se destacar também a queda das menções aos hidrocarbonetos, já que o gás natural deixou de ser o principal recurso nas negociações entre os dois países, e o petróleo que não apareceu nenhuma vez.

Gráfico 5: Número de Vezes em que os Recursos Energéticos Foram Contemplados no Governo FHC

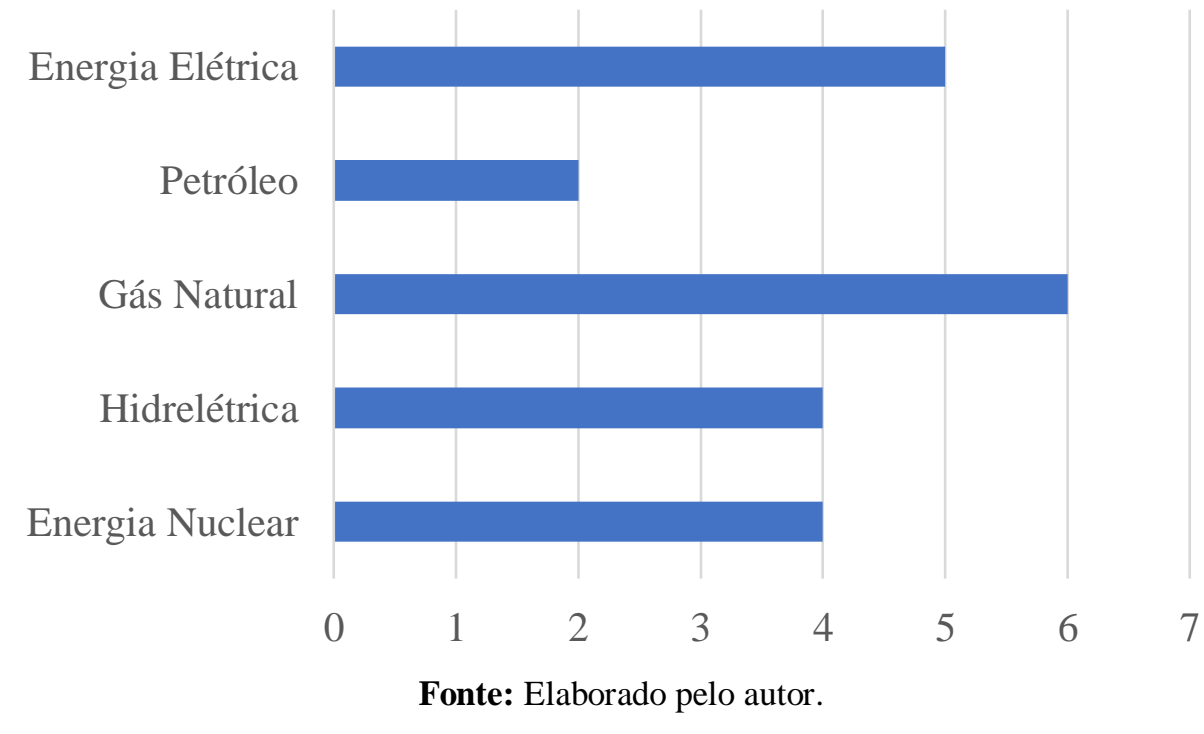

Revista Brasileira de Políticas Públicas e Internacionais, v.4, n.1, julho/2019, pp. 82-104. 
FEITOSA, Lucas Marques. Análise dos Acordos Assinados pelo Brasil e pela Argentina na Área de Energia entre 1995 e 2010.

Gráfico 6: Número de Vezes em que os Recursos Energéticos Foram Contemplados no Governo Lula

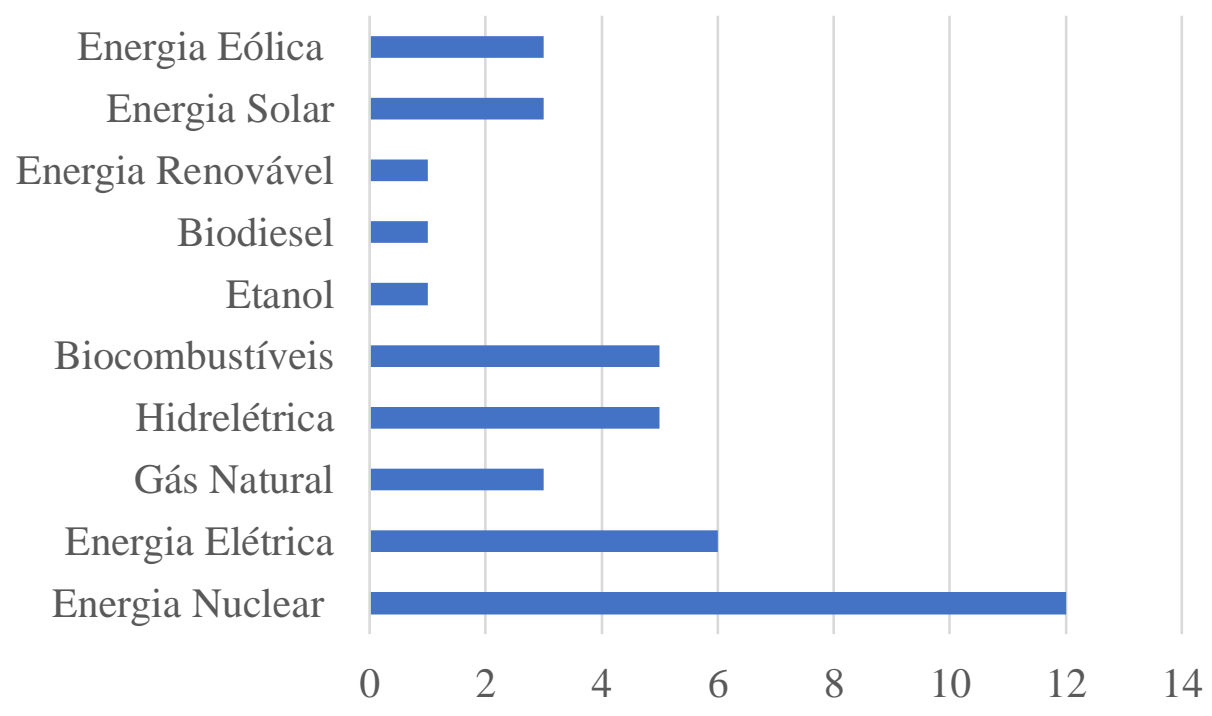

Fonte: Elaborado pelo autor.

Por último no que diz respeito aos números encontrados na pesquisa, será exposto quais foram os tipos de documentos assinados. É importante ter esse tipo de informação pois dependendo do tipo do conteúdo presente no ato, adotam-se diferentes nomes. Eles podem variar entre acordos, tratados, ajustes, protocolos, memorandos de entendimento, entre outros. Cada um deles representa uma forma diferente de concordância entre as partes. Os tratados, por exemplo, são acordos internacionais feitos de forma bilateral ou multilateral. Ao realizarem esses atos os países buscam atribuir importância política ao que foi estabelecido. Os acordos, por sua vez, estabelecem base institucional para a cooperação entre os países. Os memorandos de entendimento seriam atos realizados de forma simplificada que buscam estabelecer princípios gerais de como as relações entre as partes devem ser conduzidas em diferentes planos (Brasil, 2017). Já os comunicados conjuntos, são comunicados que são feitos quando os chefes de Estado das partes se reúnem e expõem o que foi acordado durante as negociações entre os países. Entre 1995 e 2002 observa-se que 50\% dos atos assinados foram Comunicados Conjuntos. Isso exemplifica que metade dos atos assinados derivaram de encontros entre FHC e o presidente da Argentina no período. Observa-se também a presença de dois acordos, um protocolo de intenções, uma ata e um memorando de entendimento.

Revista Brasileira de Políticas Públicas e Internacionais, v.4, n.1, julho/2019, pp. 82-104. 
FEITOSA, Lucas Marques. Análise dos Acordos Assinados pelo Brasil e pela Argentina na Área de Energia entre 1995 e 2010.

Durante o governo Lula os comunicados conjuntos permanecem sendo o principal ato assinado referente a temática energética, reafirmando o que foi dito anteriormente que durante os seus encontros com Chefes de Estado de outros países a temática energética era leva à tona. No entanto, merece atenção também o fato de terem sido realizados três protocolos adicionais com a Argentina. Isso significa que foram realizadas alterações em tratados já realizados anteriormente buscando aprimorar a cooperação entre ambos os países. Os números gerais dos atos realizados nos dois governos podem ser observados nos gráficos 7 e 8 .

Gráfico 7: Tipo de Ato Assinado e a Quantidade de Vezes que Ele Foi Realizado no Governo FHC

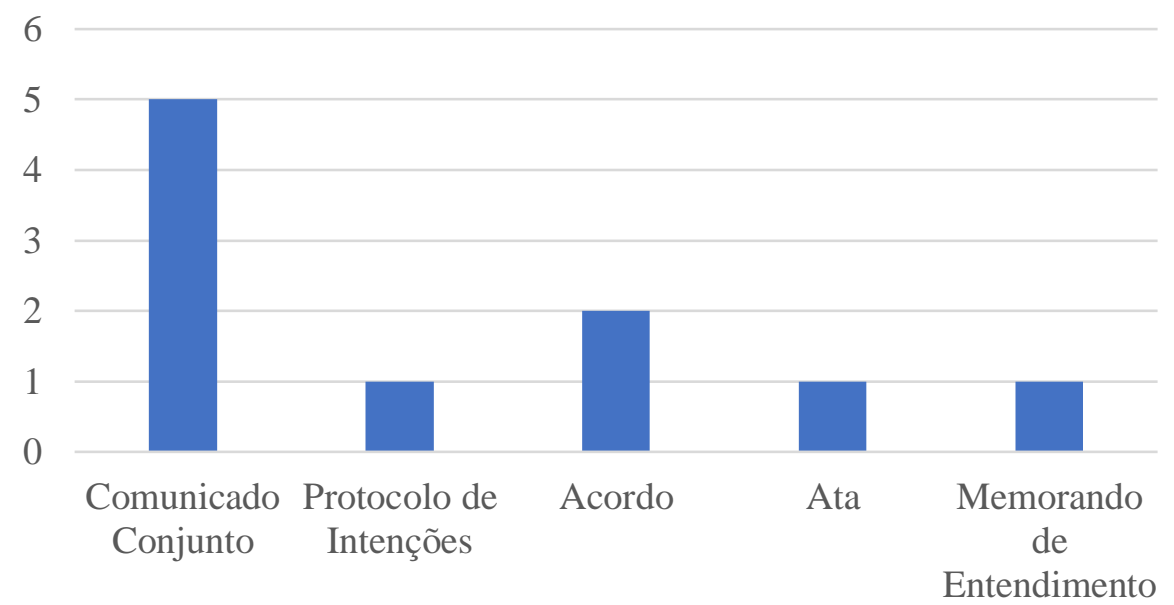

Fonte: Elaborado pelo autor.

Gráfico 8: Tipo de Ato Assinado e a Quantidade de Vezes que Ele Foi Realizado no Governo Lula

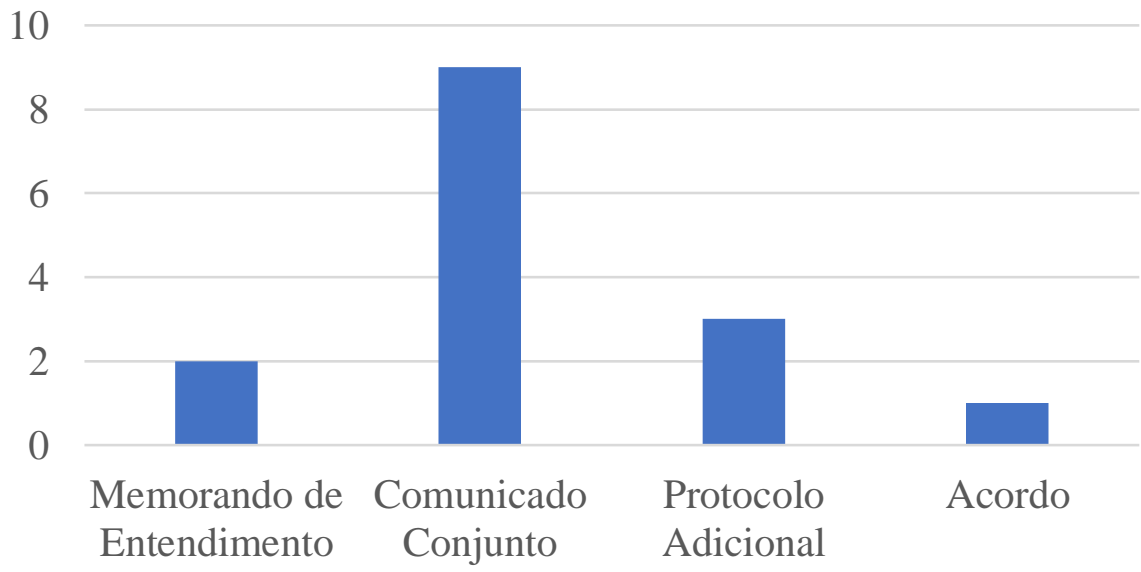

Fonte: Elaborado pelo autor.

Revista Brasileira de Políticas Públicas e Internacionais, v.4, n.1, julho/2019, pp. 82-104. 
FEITOSA, Lucas Marques. Análise dos Acordos Assinados pelo Brasil e pela Argentina na Área de Energia entre 1995 e 2010.

Portanto, sabendo desses números gerais sobre os atos bilaterais assinados entre os dois países, agora será feita uma análise sobre o corpo desses documentos de forma que seja possível ter uma noção de como ocorria essa cooperação. Devido à grande quantidade de atos foi realizado um recorte de três atos de temática única ou relevante de cada governo que exemplificam bem o objetivo da cooperação energética em cada um deles. Enquanto no governo FHC essa era uma cooperação para atender uma demanda interna de energia baseada na integração energética e na livre comercialização entre os países, no governo Lula ela ocorria com o intuito de promover uma cooperação no que tange à energia nuclear e os biocombustíveis, promovendo tanto o uso da energia nuclear para fins pacíficos, como também a cooperação técnica e científica no que tange esses recursos.

$\mathrm{O}$ primeiro ato que merece atenção de acordo com as diretrizes estabelecidas anteriormente é o Acordo entre a República Federativa do Brasil e a República Argentina sobre Cooperação em Matéria Ambiental ${ }^{5}$. Esse é um ato de temática relevante assinado no dia 09 de abril de 1996 em que os dois países concordam em promover tanto novos projetos para a integração energética, por meio de usinas hidrelétricas, de reconversão, de gasodutos e oleodutos, como também um intercâmbio científico com foco no uso de combustíveis fósseis e fontes alternativas de energia. O segundo ato aqui analisado é o Protocolo de Intenções entre os Governos do Brasil e da Argentina sobre Cooperação e Interconexão Energéticas ${ }^{6}$ assinado também no dia 09 de abril de 1996. Nesse protocolo de intenções de temática única foi estabelecido que seria realizada uma integração energética que permitiria um melhor aproveitamento dos recursos energéticos e que garantiria a regularidade do abastecimento energético brasileiro. Além disso foi determinado que seria promovida a livre transação de energia elétrica e de gás natural entre as empresas dos dois países e seria utilizado o gás natural argentino que fosse excedente para atendar a demanda interna brasileira. $O$ último ato a se analisar é o Memorando de Entendimento sobre o Desenvolvimento de Intercâmbios Elétricos e Futura Integração Elétrica ${ }^{7}$, ato de temática única assinado no dia 13 de agosto de 1997, em que o Brasil e a Argentina se comprometem em desenvolver intercâmbios bilaterais em matéria de

\footnotetext{
${ }^{5}$ Disponível em: 〈https://concordia.itamaraty.gov.br/detalhamento/4238>

${ }^{6}$ Disponível em: <https://concordia.itamaraty.gov.br/detalhamento/4234>

${ }^{7}$ Disponível em: <https://concordia.itamaraty.gov.br/detalhamento/4374>
}

Revista Brasileira de Políticas Públicas e Internacionais, v.4, n.1, julho/2019, pp. 82-104. 
FEITOSA, Lucas Marques. Análise dos Acordos Assinados pelo Brasil e pela Argentina na Área de Energia entre 1995 e 2010.

energia elétrica entre os mercados de ambos os países, visando a complementação de seus recursos energéticos, como também buscam assegurar condições competitivas ao mercado de geração de eletricidade, sem a imposição de subsídios que possam alterar as condições normais de concorrência.

No tocante aos acordos realizados no governo Lula, um primeiro ato que merece destaque é a Declaração Conjunta dos Senhores Presidentes da República Federativa do Brasil e da República Argentina ${ }^{8}$. Nessa declaração de temática relevante é reforçado o uso da energia nuclear para fins pacíficos e é aprofundada as relações dos agentes técnicos e científicos dos dois países para propiciar a colaboração dos países no mercado regional. Um segundo ato para ser discutido aqui é a Declaração conjunta visita de Estado ao Brasil da Presidenta da República Argentina, Cristina Fernandez de Kirchner $^{9}$ assinada no dia 23 de abril de 2009. Nessa declaração determinou-se que seria promovida a integração dos sistemas energéticos e do desenvolvimento dos biocombustíveis entre os dois países. Além disso decidiu-se que deveria ser realizada a criação de um Programa Bilateral de Energias Novas e Renováveis, que incluiria a capacitação de recursos humanos em nível de pós-graduação, pesquisas na produção de biocombustíveis, em energias provenientes do sol, dos ventos, do mar e dos rios, assim como em novas tecnologias associadas à economia do hidrogênio e ao uso racional de energia. Por último, merece destaque a Declaração de San Juan ${ }^{10}$, ato de temática relevante assinado em 03 de agosto de 2010, em que foi registrado os avanços na elaboração do Plano de Trabalho Científico-Tecnológico, no marco das áreas definidas como prioritárias do Programa Bilateral de Energias Novas e Renováveis e na definição de projetos na área de produção de hidrogênio a partir de álcoois e pequenas centrais hidrelétricas.

\section{Considerações finais}

Durante esse trabalho foram apresentadas discussões que envolvem a segurança energética e a importância da cooperação entre os países para que seja possível alcança-la. Além disso, observou-se a política externa de FHC e de Lula de forma que fosse possível

${ }^{8}$ Disponível em: <https://concordia.itamaraty.gov.br/detalhamento/5036>

${ }^{9}$ Disponível em: <https://concordia.itamaraty.gov.br/detalhamento/6223>

${ }^{10}$ Disponível em: <https://concordia.itamaraty.gov.br/detalhamento/6901>

Revista Brasileira de Políticas Públicas e Internacionais, v.4, n.1, julho/2019, pp. 82-104. 
FEITOSA, Lucas Marques. Análise dos Acordos Assinados pelo Brasil e pela Argentina na Área de Energia entre 1995 e 2010.

entender as diferenças entre elas. Por meio dessas duas discussões foi possível realizar uma análise sobre os acordos realizados pelo Brasil e pela Argentina entre 1995 e 2010 procurando encontrar semelhanças e diferenças entre os dois governos. Apesar de ser uma análise descritiva ainda superficial sobre o tema, o material aqui adotado permite a realização de um estudo mais inferencial.

O que é possível concluir inicialmente é que a segurança energética apesar de ser muito importante para os países, ainda é um conceito vago ou multifacetado de acordo com Johansson (2013). Contudo, pode-se dizer que, apesar de a sua definição se modificar de acordo com a forma que os Estados a enxergam, é possível afirmar de forma resumida que ela trata sobre como os países vão conseguir suprir as necessidades energéticas dentro da sua sociedade, sem sofrer maiores consequências caso haja algum problema interno ou externo.

Sobre a comparação realizada entre as políticas externas dos dois ex-presidentes discutidos nesse trabalho, verificaram-se tanto continuidades como descontinuidades. Percebeu-se que houveram mudanças de paradigmas nos dois períodos, sendo da autonomia pela distância para a autonomia pela integração nos governos de FHC, como também da autonomia pela distância para a autonomia pela diversificação com Lula. Contudo, ainda era clara a importância da Argentina independente do presidente que estava no poder, sendo modificada somente a forma como era realizada a política externa em torno dela.

Já sobre a análise dos acordos energéticos é possível afirmar inicialmente que no governo Lula a Argentina recebeu maior atenção do que no governo FHC para a cooperação energética. Como pôde ser visto nos gráficos 1 e 2, no governo FHC a Argentina dividia a atenção da cooperação energética brasileira com países como Bolívia e Venezuela, mesmo sendo a primeira em termos de números, contudo, no governo Lula a Argentina passa a ter números de atos assinados com o Brasil muito maiores do que os demais países da região.

Outro ponto que ficou evidente na análise dos acordos é que no governo FHC a presença dos hidrocarbonetos ainda é relevante. O Brasil possuía uma alta dependência externa desses recursos e via a Argentina como uma possível saída para importar o gás natural demandado pelo país, por exemplo. Isso se modifica durante o governo Lula que passa a utilizar os bicombustíveis como fonte de influência não só com a Argentina, mas com diversos

Revista Brasileira de Políticas Públicas e Internacionais, v.4, n.1, julho/2019, pp. 82-104. 
FEITOSA, Lucas Marques. Análise dos Acordos Assinados pelo Brasil e pela Argentina na Área de Energia entre 1995 e 2010.

países ao redor do mundo. A descoberta de petróleo e gás natural na camada pré-sal pode ter sido também outro fator que influenciou a diminuição da cooperação ao redor dos hidrocarbonetos, já que dessa forma acreditava-se que o Brasil poderia ter sua autossuficiência nesses recursos, podendo dispensar a importação de países vizinhos.

Por último, ao analisar o corpo dos documentos assinados, conclui-se que a noção de segurança energética utilizada pelo Brasil com a Argentina durante o governo FHC era de atender a demanda interna do país por meio da importação de recursos e da integração das linhas elétricas entre ambos, já que dependência externa do país em 1995 significava 30,2\% da demanda total do país (MME, 2003). Enquanto isso, durante o governo Lula a dependência externa do Brasil por energia chegou a ser de somente 3,9\% da demanda total do país, modificando a noção de segurança energética brasileira, na qual passou a se desenvolver em torno da cooperação técnica e científica para o desenvolvimento de novas formas de energia e do melhor aproveitamento de recursos já existentes na região.

\section{Referências}

Almeida, P. R. de (2004). Uma política externa engajada: a diplomacia do governo Lula. Revista Brasileira de Política Internacional, 47 (1), 162-184.

Angulo, S. L. C (2011). Complementarity and Integration of the Energy in South America. A Juridical Analysis Based on the Factors that Obstruct the Market Integration, Germany (Tese de Doutorado). Faculdade de Direito da Universidad de Chile, Chile.

Barton, B (2004). Introduction. In: Barton, B., Redgwell, C., Rønne, A., \& Zillman, D. N. Energy Security: Managing Risk in a Dynamic Legal and Regulatory Environment (pp. 3-13). Oxford: Oxford University Press.

Barufi, C. B., Santos, E. M. dos, \& Ide, C. R. (2006). AutoSuficiência Energética e Desenvolvimento: o Comércio de Gás Natural entre Brasil e Bolívia. Cadernos Prolam/usp, São Paulo, v. 2, 183-208.

Beltrame, C. (2008). O Etanol na Diplomacia Presidencial do Governo Lula (Trabalho de Conclusão de Curso). Universidade do Vale do Itajaí, Brasil.

Braga, J. L. R. (2017). A emergência da América do Sul na agenda da política externa brasileira nos governos Lula da Silva (2003-2010). Espaço e Economia, 10.

Revista Brasileira de Políticas Públicas e Internacionais, v.4, n.1, julho/2019, pp. 82-104. 
FEITOSA, Lucas Marques. Análise dos Acordos Assinados pelo Brasil e pela Argentina na Área de Energia entre 1995 e 2010.

Brasil (2017). Atos Internacionais. Recuperado em 15/07/2019, de http://brasil.gov.br/governo/2012/05/atos-internacionais.

Chaudry, M., Ekins, P., Ramachandran, K., Shakoor, A., Skea, J., Strbac, G., Wang, X., \& Whitaker, J. (2011). Building a Resilient UK Energy System. Uk Energy Research Centre.

Castro, N. J., Rosental, R., Brandão, R., Dantas, G. de A., \& Leite, A. L. da S. (2014). Importância e Dificuldades da Integração Elétrica na América do Sul. In: Desiderá Neto, W. A., \& Teixeira, R. A. (Org.). Perspectivas para a Integração da América Latina (pp. 115-126). Brasília: Instituto de Pesquisa Econômica Aplicada.

Chester, L. (2010, novembro). Conceptualising energy security and making explicity its polysemic nature. Energy Policy, 38 (2), 887-895.

Ciuta, F. (2010, abril). Conceptual Notes on Energy Security: Total or Banal Security? Security Dialogue, 41 (2), 123-144.

Concórdia (2019). Atos Internacionais Firmados com a Argentina na Temática Energética. Ministério das Relações Exteriores. Recuperado de https://concordia.itamaraty.gov.br/.

Farias, T. G. de (2011, janeiro/junho). A sul-americanidade da política externa brasileira no Governo de Fernando Henrique Cardoso. Univ. Rel. Int., Brasília, 9 (1), 247-272.

Granato, L. (2012, agosto/dezembro). As Relações Bilaterais Argentino-brasileiras no Quadro da Integração Regional: de um Quadro de Rivalidade ao Despertar de uma Efetiva Cooperação. Revista Cadernos de Estudos Sociais e Políticos, 1 (2), 69-95.

Hage, J. (2011). Integração física regional e biocombustíveis. Meridiano 47 - Journal of Global Studies, 8 (89), 6-8.

Johansson, B. (2013, maio). A broadened typology on energy and security. Energy, 53, 199205.

Medeiros, D. M. (2009). O etanol e o petróleo no processo de inserção internacional do Brasil no governo Lula. Simpósio de Pós-Graduação em Relações Internacionais do Programa "San Tiago Dantas” (UNESP, UNICAMP e PUC/SP). São Paulo, SP, Brasil, 2.

Ministério de Minas e Energia (MRE) (Ed.) (2003). Balanço Energético Nacional 2003. Brasília: Ministério de Minas e Energia.

Energia.

(2011). Balanço Energético Nacional 2011. Brasília: Ministério de Minas e

Revista Brasileira de Políticas Públicas e Internacionais, v.4, n.1, julho/2019, pp. 82-104. 
FEITOSA, Lucas Marques. Análise dos Acordos Assinados pelo Brasil e pela Argentina na Área de Energia entre 1995 e 2010.

Paiva, I. (2010). Acordos de cooperação internacional como estratégia de política externa brasileira para a promoção do mercado de biocombustível nacional. Congresso Brasileiro de Direito Internacional, Foz do Iguaçu, PR, Brasil, 8.

Pergher, H. (2016). A integração energética na América do Sul: Uma análise das políticas de integração energética promovidas no MERCOSUL e na UNASUL. RICRI, João Pessoa, 3 (6), 58-82.

Ribeiro, R. A. (2015, agosto). A Energia na Política Externa Brasileira. Neiba, 4 (1), 45-58.

Rodrigues, L. A. (2012). Análise institucional e regulatória da integração de energia elétrica entre o Brasil e os demais membros do MERCOSUL (Dissertação de Mestrado). Programa de Pós-graduação em Energia - EP / FEA / IEE / IF, Universidade de São Paulo, São Paulo, SP, Brasil.

Santos, T., Albuquerque, R., \& Santos, L. (2013). Integração Regional e Cooperação Energética na América do Sul. Encontro Nacional da Associação Brasileira de Relações Internacionais, Belo Horizonte, MG, Brasil, 4.

Scheibe, E. F. (2008). Biocombustíveis e Política Externa Brasileira: Coerência Histórica Entre Política Energética e Política Externa e o Papel dos Grupos de Interesse na Questão dos Biocombustiveis (Trabalho de Conclusão de Curso). Universidade Federal do Rio Grande do Sul, Porto Alegre, RS, Brasil.

Simões, A. J. F. (2007). Biocombustíveis: A Experiência Brasileira e o Desafio da Consolidação do Mercado Internacional. In: BRASIL. Ministério das relações exteriores MRE (Org.). Biocombustíveis no Brasil: realidades e perspectivas (pp. 10-33). Brasília: Arte Impressora Gráfica LTDA.

Soares, S. S. D., \& Estensoro, M. P. (2014). Apresentação. In: Desiderá Neto, W. A. (Org.). Perspectivas para a Integração da América Latina. Brasília: Ipea.

Vigevani, T., \& Cepaluni, G. (2007, julho/dezembro) A Política Externa de Lula da Silva: A Estratégia da Autonomia pela Diversificação. Contexto Internacional, Rio de Janeiro, 29 (2), 273-335.

Vigevani, T., \& Oliveira, M. F. de (2003). A Política Externa Brasileira na Era FHC: Um Exercício de Autonomia pela Integração. Interthesis, 1-44.

Yergin, D. (2006, março/abril). Ensuring Energy Security. Foreign Affairs, 85 (2), mar/abr: 6982.

Revista Brasileira de Políticas Públicas e Internacionais, v.4, n.1, julho/2019, pp. 82-104. 